\title{
ANALYSIS OF WORK EFFICIENCY IN HARD COAL MINING IN POLAND
}

\section{Aurelia Rybak $^{1}$, Ewelina Wlodarczyk ${ }^{2}$}

\begin{abstract}
:
Motivation: This article presents the analysis of work efficiency in hard coal mining in Poland. Labour costs in Polish mining enterprises account for over $40 \%$ of the total production cost. For this reason, the labour productivity of employees has a key impact on the final operating profit.

Problem statement: In the case of Polish coal companies, the efficiency is the index value of which particular restructuration programs have attempted to increase for years. However, because of the effect of overstaffing and a decrease in hard coal exploitation, the task was impossible.

Approach and results: In this article the effects of the latest recovery programme have been presented, the production efficiency index has been determined; the rate of changes in production volume has been presented as well as the employment figure and the average salary in the Polish mining industry in the recent decade. Moreover, the prognosis of the employment figure using the ARIMA and ARMAX class model was conducted.

Conclusions: It should be noted that in the last four years a significant reduction in the employment figure has been onserved in the hard coal mining industry. This figure has been adjusted to the production volume level. This, in turn, has positively influenced the work efficiency coefficient level.
\end{abstract}

JEL Classification Numbers: E24, J53; DOI: http://dx.doi.org/10.12955/cbup.v6.1192

Keywords: KPI, work efficiency, ARIMA Model

\section{Introduction}

In conditions of a turbulent environment of a company, it is necessary to permanently control the company's functioning and efficiency in regard to the level of set targets which have been implemented. Controlling is a modern method of company management, based on the creation and updating of the planning system architecture, construction of indexes, measurements of the financial situation, and the preparation of current and strategic information used for making decisions (Penc, 1994). Controlling is conducted on the grounds of indexes, which allow the measurement of the company's achievement level in regard to its targets. Such indexes are called KPI - Key Performance Indicators.

They are a set of tools facilitating the management of every area of a company (Grycuk, 2010). The indicators make it possible for a company to quickly detect irregularities of processes occurring in it. KPIs are a large group of indexes of which best characterize the examined phenomena. Production efficiency is one of key KPI indicators. It is a very important measure of the appropriate use of the held production resources. Therefore, the authors of this article wanting to trace the effects of the hard coal mining restructuring process in Poland used KPI indicator in this article. The information about irregularities occurring in a company makes it possible to correct strategies and organization targets. The coal mining industry has been in a difficult situation for many years. Since 1989 many attempts to restructure it have taken place. However, usually the lack of perseverance in the consistent introduction of the planned changes and changing Governments caused failure in achieving the desired effects of every restructuring. Solving problems with the inefficiency of hard coal exploitation was also disregarded in periods of prosperity, when the price of coal significantly exceeded the huge total costs of production and allowed for achieving profit despite unfavourable conditions of conducting the exploitation. One should bear in mind that these conditions refer to the economic side of the production process - the costs structure, large share of permanent costs in the total cost and constantly deteriorating geological conditions of the exploitation. The recent crisis of the fuel market and the decreasing process of raw energy materials forced the taking of relevant steps aimed at restoring the profitability of the hard coal mining industry in Poland. The organizational structure of the biggest coal companies in Poland was changed - Coal Company and Katowice Coal Holding were transformed into the Polish Mining Group. Unprofitable mines were forwarded to the Mine Restructuring Company which was formed to liquidate the selected mines and manage their property.

\footnotetext{
${ }^{1}$ Silesian University of Technology Faculty of Mining and Geology, Department of Electrical Engineering and Automation in Industry, aurelia.rybak@ polsl.pl

${ }^{2}$ Silesian University of Technology Faculty of Mining and Geology, Department of Safety Engineering, ewelina.wlodarczyk@polsl.pl
} 


\section{Data and methodology}

Until recently Polish hard coal mines were producing more hard coal than there was demand. Thus, the coal was stored in so-called heaps. The excessive employment figure, huge production costs, no profit from sale and additionally lost opportunity costs connected with the need to store overproduction put coal companies in a very uncomfortable financial position. Considering the above, it became necessary to limit the production capacity. Such operations have been made practically since 1989; nevertheless, they have not caused any decrease in the production costs or an increase in the work efficiency. In order to verify the restructuration effects conducted in the Polish mining industry in the last two years, the authors of this article used KPI, i.e. the work efficiency indicator. The results obtained on the grounds of using KPI indicators are support for the decision-making process in the company, they also facilitate the identification of irregularities and enable the selection of relevant means to reduce the detected problems. Thanks to these indicators, managers have the possibility to make more effective decisions regarding the management of company resources. KPI indicators facilitate the strategic management as well as the operational activity of the company. KPI include a set of financial and non-financial indicators (Rydzewska-Włodarczyk \& Sobieraj, 2015). They can be divided into the following groups:

- Information-operational, such as average machine age, timelines of overhauls and reviews.

- Economic - profitability indicators, permanent and variable costs.

- Technical-exploitation, among others, efficiency indicators, the standstill time of machines indicator, defects and failure of machines indicator.

- Safety, such as number of accidents, number of threats (Antosz \& Stadnicka, 2015).

The indicators are used to measure the efficiency and effectiveness of actions subjected to the company analysis. Table 1 shows the results of measuring the employment decline rate in hard coal mining in Poland. The increase in the rate of this phenomenon occurred after 2012, whereas in the recent two years its level increased three times in comparison to 2012.

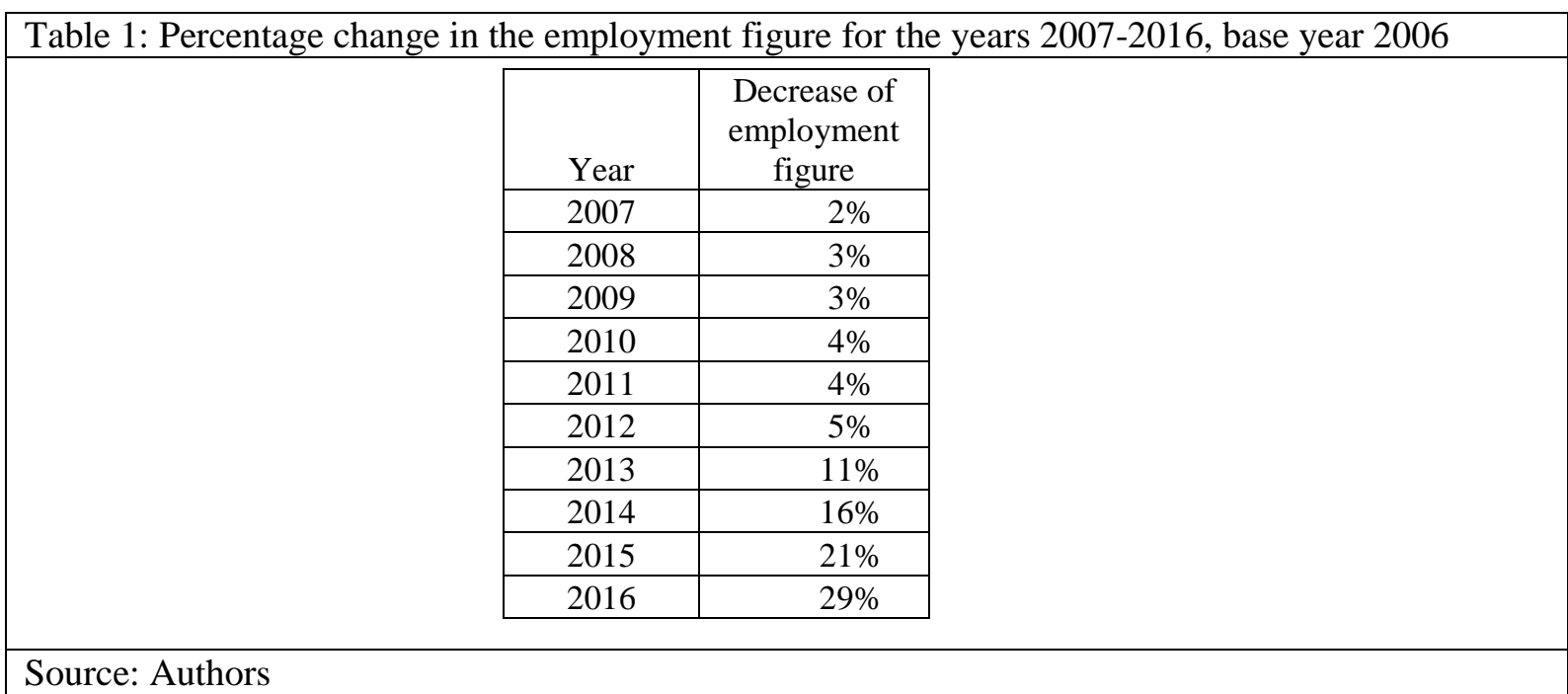

In this case it is necessary to verify the effects of the decrease in the employment figure. Thus, it was checked how it influenced the efficiency of work in the mining industry. For this purpose, the KPI indicator of work performance - determined as the ratio of coal exploitation volume and the employment volume was used.

$$
W_{p}=\frac{P}{E}
$$

where:

$\mathrm{W}_{\mathrm{p}}$ - work performance;

$\mathrm{P}$ - production volume;

$\mathrm{E}$ - employment volume. 
Figure 1 presents the employment volume and the work performance in years 2003-2016. A definite change of development of these phenomena also after 2012 can be noticed. At that time the modification of the direction of the development tendency occurred both in the performance and the employment volume. The employment volume starts falling, which of course resulted in an increase in the work performance.

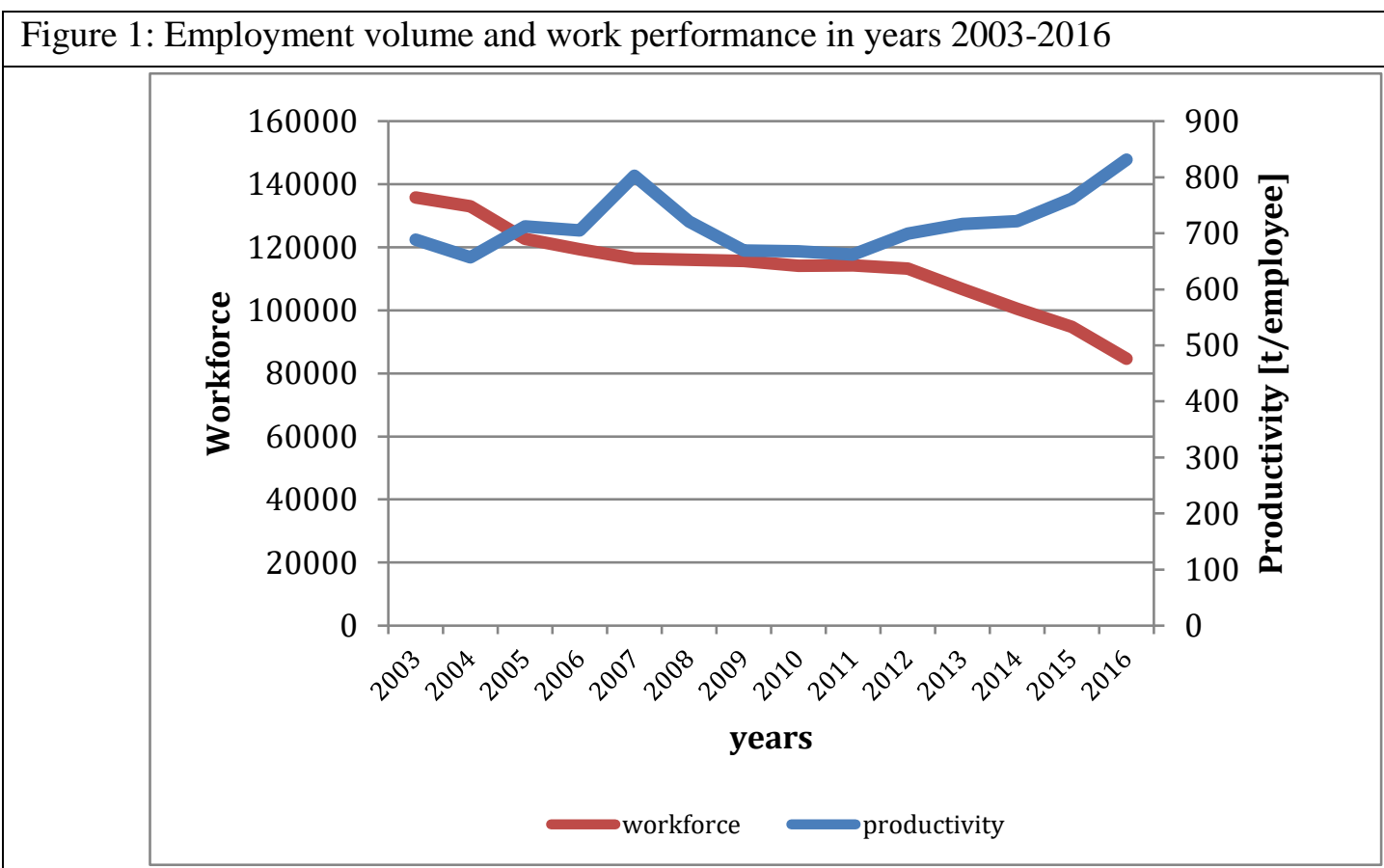

Source: Authors

Table 2 presents the remuneration and hard coal exploitation volume over the last ten years. At that time the production capacity was limited, and it decreased by $25 \%$ compared to 2007 . However, the remuneration constantly increased.

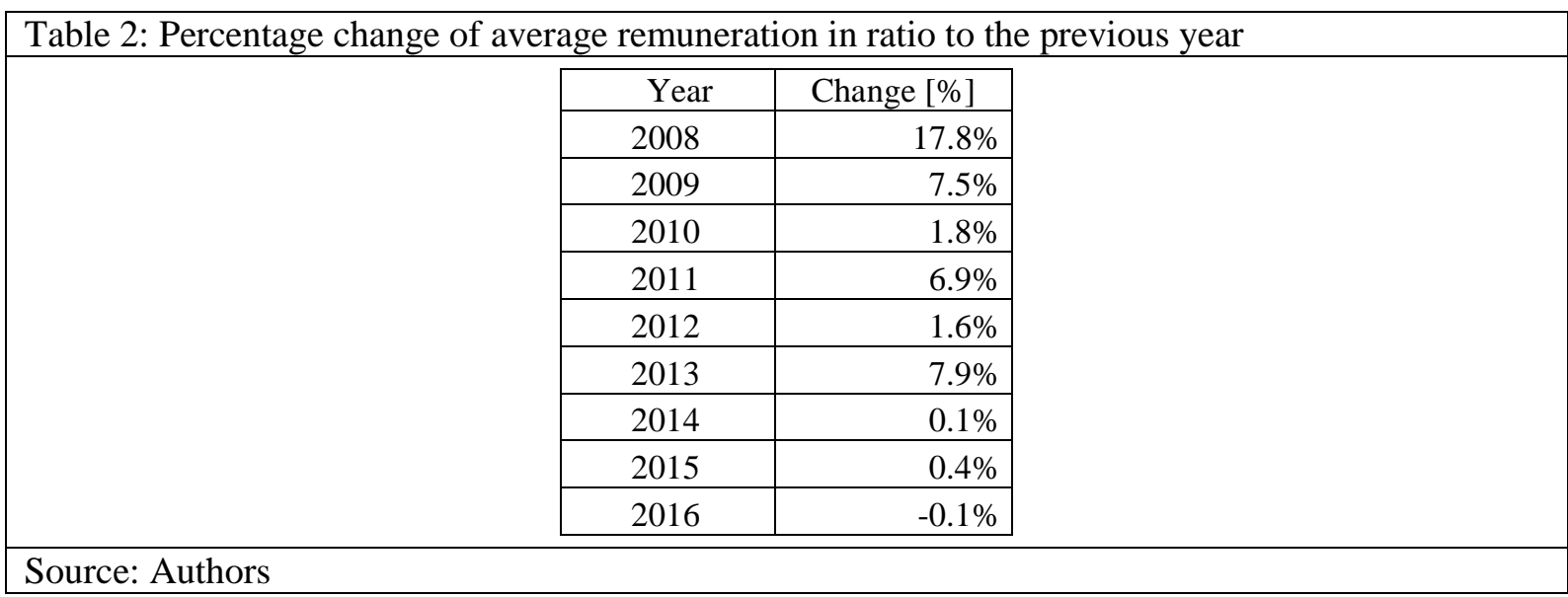

Despite the increase of average remuneration in the hard coal mining industry the rate of this increase significantly decreased over the last 10 years. In addition, since 2014 wages have practically not increased (below 1\%).

In conformity with the predictions of experts, in the forthcoming years the mining industry in Poland may have a problem with a quickly decreasing level of employment. In order to scientifically confirm this hypothesis, the authors created a forecast of the employment level by 2021.. To forecast the employment volume, a model of class ARIMA $(1,1,0)$ was used. The first stage of forecasting was the selection of the relevant ARIMA model, bringing the time series to the stationary character, and the selection of the optimal model parameters (Kufel, 2011). 

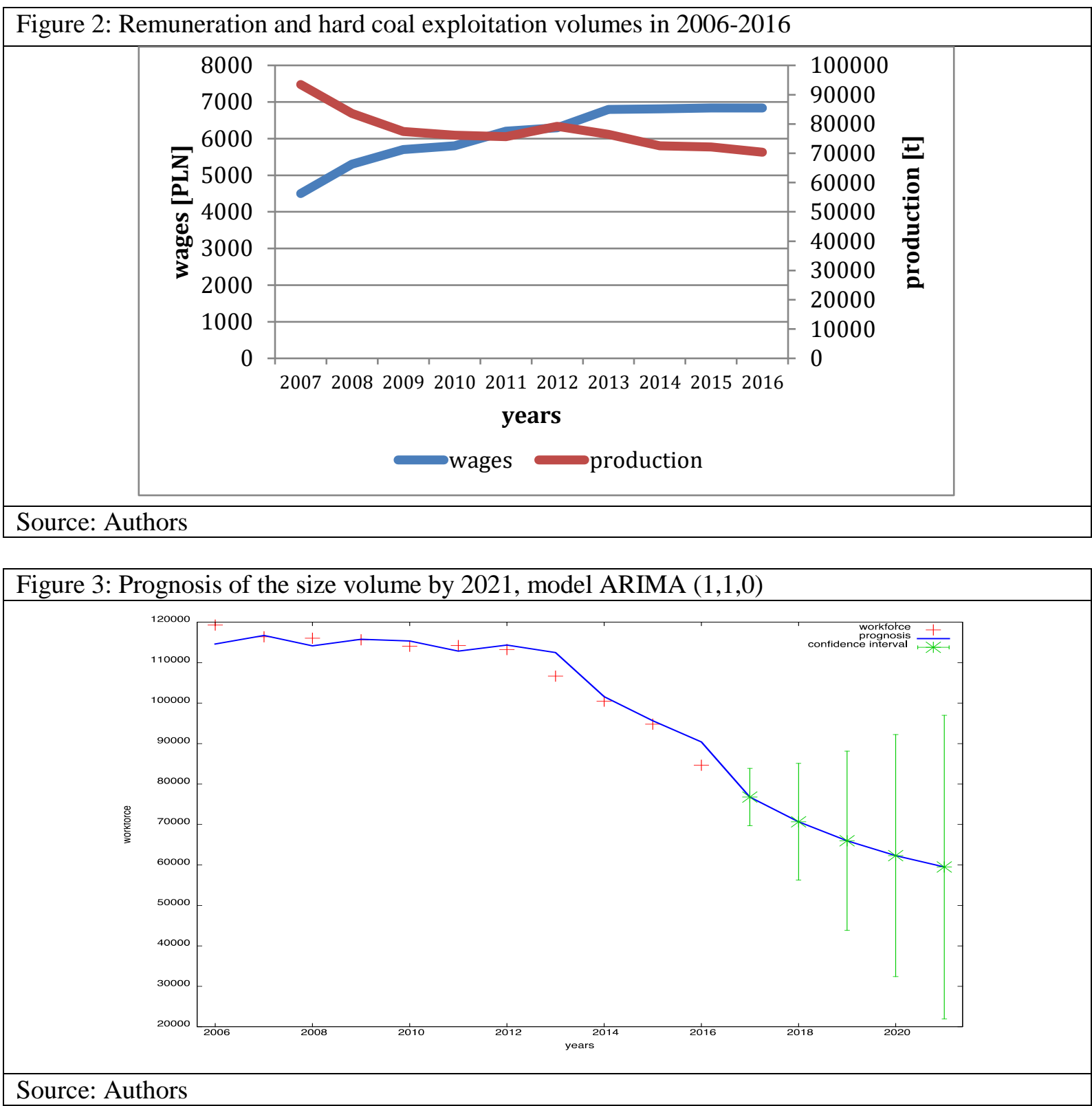

Since the environment of coal companies in Poland is characterized by a high instability level, when forecasting the future one should not use a single prognosis but a set of possible alternative scenarios which may occur.. Figure 3 presents the prognosis of the employment volume and the prognosis confidence interval, which can be assigned to two extreme scenarios; the optimistic (interval over the prognosis data series) and pessimistic (interval under the prognosis data series). The prognosis confidence interval is the scope in which, with a certain assigned probability, the value which is being forecast will be located. For example, if the employment volume in 1 year of the prognosis is from 6,970 to 8,535 people with a 95 -percent interval, it means that with $95 \%$ probability the employment volume will amount at least 6,970 at most 8,535 people. The information criteria enable the selection of the best model for a dependent variable. It is assumed that the best model is this for which the information criteria value is the lowest. The most commonly used criteria are AIC (Akaike Criterion), BIC (Bayesion/Schwartz Information Criterion) and Hannan Qiunn Criterion (Piłatowska, 2010). The criteria values for the finally chosen model are the following:

- $\mathrm{AIC}-257.80$

- Hannan Quinn - 257.57

- $\mathrm{BIC}-258.93$

In order to determine the forecast precision, the mean absolute percentage error (MAPE) was determined (Witkowska, 2006). 
$M A P E=\frac{1}{m} \sum_{t=1}^{m}\left|\frac{y_{t}-y_{t}^{P}}{y_{t}}\right| \cdot 100$

where:

$y_{t}$ - real value of the employment volume;

$y_{t}^{P}$ - forecast value;

$\mathrm{m}$ - number of observations.

MAPE error is approximately 3\%, which means a high precision series model was created.

A properly constructed, reliable prognosis will let the company adjust the employment volume to the market requirements and eliminate wastage. However, in order to create adequate employment plans the company must be aware of what the potential factors which could shape the employment level in the company. Therefore, the authors of this paper presented the ARMAX model, which makes it possible to consider many explanatory variables in the creation of a prognosis (Reinsel, 2003; Marmarelis \& Mitsis, 2014). When creating the model, the remaining variables presented in the article, such as the production volume and the average wages, were taken into account. Because the average wages did not demonstrate statistical significance, for the final model only the additional explanatory variable - the production volume was chosen. Figure 4 presents the results of the prognosis created on the grounds of the ARMAX model. As can be noted, if the employment volume is adjusted in the Polish mining industry to the size of forecast exploitation after 2017, the employment volume should reach a continuous, stable level. It is concurrent with the prognosis concerning the production volume created by the authors. These prognoses were made, among others, using the Boltzmann sigmoidal model. According to the results in the nearest years the production volume in Poland will also oscillate around a stable level.

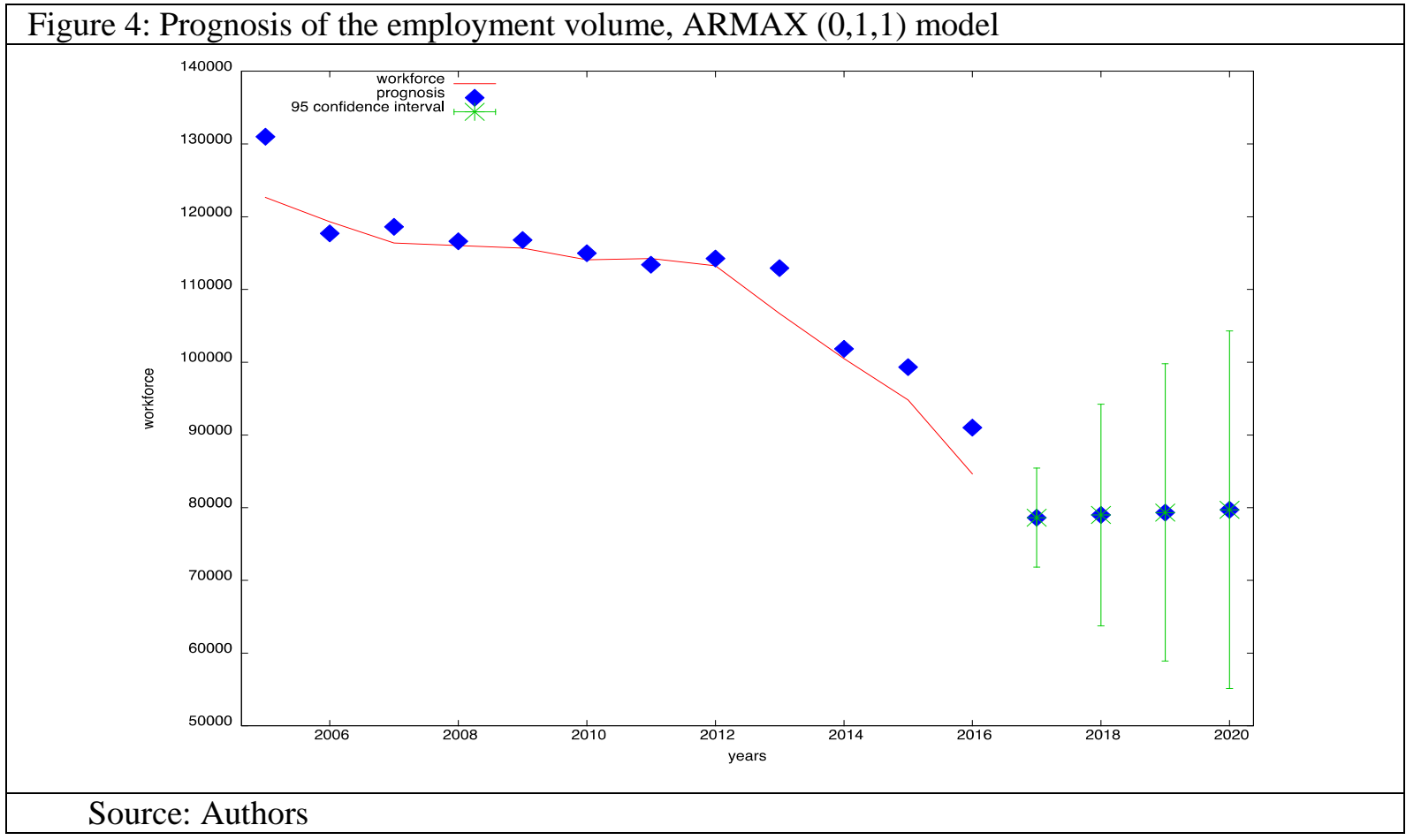

The correlation coefficient was determined for the employment and production volumes (Paradysz, 2005).

$$
r_{x y}=\frac{\sum_{i=1}^{n}\left(x_{i}-\bar{x}\right)\left(y_{i}-\bar{y}\right)}{\sqrt{\sum_{i=1}^{n}\left(x_{i}-\bar{x}\right)^{2} \sum\left(y_{i}-\bar{y}\right)^{2}}}
$$


where:

$\mathrm{r}_{\mathrm{xy}}$ - correlation coefficient;

$\mathrm{x}_{\mathrm{i}}, \mathrm{y}_{\mathrm{i}}$ - $\mathrm{i}$ - these observation values from $\mathrm{x}, \mathrm{y}$ population (i.e. employment and coal production).

$\bar{x}, \bar{y}$ - means of $\mathrm{x}, \mathrm{y}$ population.

The following results were obtained:

- Correlation coefficient for variables in years 2003-2013 is 0.7.

- Correlation coefficient for variables in years 2003-2016 is 0.82 .

The calculated data shows that up to 2013 inclusive, the relation between the examined populations, i.e. the levels of employment and production was moderate. The correlation up to 2016 demonstrates restructuring activities conducted in the recent three years. The dependence on 0.82 correlation coefficient level may be considered quite strong.

Over-employment was liquidated and the level of demand for hard coal is now a factor that has a decisive impact on employment. The reduction of the employment figure unjustified in regard to the necessity to limit the production capacity may cause problems with preserving the continuity of exploitation. The research conducted in 2014 demonstrated a negative development trend. Despite a continuous decrease in the employment figure in mining enterprises, the share of permanent costs connected with live work was still significantly increasing (even by $130 \%$ in years 2007-2014). However, the decrease of the employment figure affected mainly underground workers, and when they left, the company lost knowledge and experience. In turn, this had a negative influence on the curve of learning. Consequently, in the mining industry occurred constant lack of labor productivity growth and reduction of average production costs (Rybak \& Rybak, 2016).

Further reduction of employment in the mining industry will be result mainly from retirement or voluntary resignations. The miners who remain in the coal companies will be transferred to places where they can work more efficiently, excluding the so-called wastage. Most probably the employment figure in the mining industry in the nearest future will be reduced in conformity with the government assumptions, because the miners are interested in taking advantage of social protection programmes offered by the State. However, it should be noted that when qualified miners retire, the problem with young workers, who have not gained experience yet and gaining it will be more difficult in such a situation, deepens. Soon the mines can lack specialists because there will be no relevant mining schools and this occupation is not attractive, so young people more and more seldom choose mining schools. One of the reasons why few people are interested in working in the mining industry is also the decrease of wages. The entire hope is the demand for coal and its prices, which since recently have allowed an optimistic look at the nearest future of the coal market in Poland. An opportunity for the Polish mining industry are investments, which could allow for an increase in work efficiency, the increase of the production volume or keeping it on a stable level with a decrease in the employment figure. Silesia mine belonging to a Czech investor will soon implement the development plan and the funds of it will amount to 200 million zlotys. In addition, the mines belonging to the State require financial investments. It is mainly the lack of funds for the development of mines that has led to their unprofitability. Without investments in new deposits the mining industry will not be able to use the probably coming prosperity for hard coal. And this time is an opportunity to prepare coal companies for the period of decreased demand for raw energy materials.

\section{Conclusion}

In the last twenty years, the Polish economy has reached one of the highest levels of work efficiency among the OECD states. Therefore, it is important for the Polish mining industry to also follow this general trend of the State development. The mining companies in Poland are functioning in very unfavourable surrounding conditions. These conditions can be described by two categories: more difficult geological conditions and unfavourable economic conditions.

To sum up, it should be noted that in the last four years a significant reduction of the employment figure was conducted in the hard coal mining industry. This figure has been adjusted to the production volume level. This, in turn, has positively influenced the work efficiency coefficient level. Nevertheless, when reducing the employment figure the necessary production capacity level should be considered. The conducted prognoses of the employment figure show that: 
- ARIMA model - considering the historical data on the employment figure the decreasing trend in this cope will continue until 2021.

- ARMAX model -considering the forecast production volume, the necessity to slow down the rate of decrease of the employment figure in mining industry should be taken into account.

Even today, employees draw attention to the fact that the mines are missing qualified staff. The lack of employees with necessary competences may negatively affect work efficiency, extend the time of particular tasks or generate more mistakes, which may cause danger to labour safety.

\section{Acknowledgements}

The work was elaborated in frames of the statutory research BK 06/030BK_18/0030.

\section{References}

Antosz, K. i Stadnicka, D. (2015). Evaluation measures of machine operation effectiveness in large enterprises: study results. Maintenance and reliability, 17(1), 107-117.

Grycuk, A. (2010). Key Performance Indicators (KPIs) as a tool to improve operational efficiency of lean-oriented manufacturing companies. 2, 28-31.

Kufel, T. (2011). Solving problems with the GRETL program. Warsaw: PWN.

Marmarelis, V. i Mitsis, G. (2014). Modeling for Diabetes: Diagnosis and Treatment. New York: Springer.

Paradysz, J. (2005). Statistics. Poznań: WAE.

Penc, J. (1994). Management strategies. Warsaw: Placet.

Piłatowska, M. (2010). Information criteria in the choice of an econometric model. Cracow: Studies and Works of the University of Economics in Cracow.

Reinsel, G. C. (2003). Elements of Multivariate Time Series Analysis. New York: Springer.

Rybak, A. M. i Rybak, A. (2016). Possible strategies for hard coal mining in Poland as a result of production function analysis. Resources Policy, 50, 27-33.

Rydzewska-Włodarczyk, M. i Sobieraj, M. (2015). Measurment of the effectivness of processes with the use of key performance indicators. Zeszyty Naukowe Uniwersytetu Szczecińskiego. Finanse, Rynki Finansowe, Ubezpieczenia(76), 333347.

Witkowska, D. (2006). Basics of econometrics and forecasting. Cracow: WOE. 